\title{
Contamination of wheelchairs by Staphylococcus aureus
}

\author{
Harumasa Hakuno ${ }^{1}$, Shigeharu $\mathrm{Oie}^{2}$, Hiroyuki Furukawa² \\ 1. Department of Pharmacy, Yamaguchi Grand Medical Center, Osaki, Hofu, Japan. 2. Department of Pharmacy, \\ Yamaguchi University Hospital, Minamikogushi, Ube, Japan
}

Correspondence: Harumasa Hakuno. Address: Department of Pharmacy, Yamaguchi Grand Medical Center, 77 Osaki, Hofu 747-8511, Japan. E-mail: hhakuno@gmail.com

Received: November 29, 2012

Accepted: December 11, 2012

Online Published: December 28, 2012

DOI : $10.5430 /$ jha.v2n2p55

URL: http://dx.doi.org/10.5430/jha.v2n2p55

\begin{abstract}
We investigated Staphylococcus aureus contamination of the hand rims and handles of wheelchairs for common use on hospital wards by wiping with gauze. Examination of the hand rims of a total of 20 wheelchairs revealed methicillin-sensitive $S$. aureus (MSSA) and/or methicillin-resistant $S$. aureus (MRSA) on 17 wheelchairs (85.0\%), and MRSA on 11 (55.0\%). The mean \pm SD (range) density of MRSA contamination was $320.8 \pm 812.3\left(2-2.8 \times 10^{3}\right)$ colony-forming units (cfu)/hand rim. Examination of the handles of the 20 wheelchairs showed MRSA on 3 (15.0\%). The incidence of $S$. aureus contamination and its density were higher on hand rims than on handles. After the hand rims were disinfected by wiping with $80 \%$ (v/v) ethanol, $S$. aureus was not detected on any of them. Since $S$. aureus may potentially be transmitted via shared wheelchairs, their disinfection after every use is recommended.
\end{abstract}

\section{Key words}

Staphylococcus aureus, Methicillin-resistant S. aureus, Wheelchair, Contamination, Disinfection

\section{I ntroduction}

There have been many studies on methicillin-resistant Staphylococcus aureus (MRSA) contamination of environmental surfaces of various apparatuses and instruments such as the side rails of beds ${ }^{[1]}$, overbed tables ${ }^{[1]}$, mattresses ${ }^{[2]}$, door handles of hospital rooms ${ }^{[3]}$, stethoscopes ${ }^{[4]}$, pens ${ }^{[5,6]}$, tourniquets ${ }^{[7]}$, and computers ${ }^{[8,9]}$. However, to the best of our knowledge, there have been no studies on MRSA contamination of wheelchairs (Figure 1) that frequently come into direct contact with the hands of patients and medical staff.

The aim of this study was to investigate $S$. aureus contamination of the hand rims and handles of shared wheelchairs used in hospital wards.

\section{Materials and methods}

Between April 2010 and January 2011, we investigated S. aureus contamination of wheelchairs on the wards of Yamaguchi Grand Medical Center (504 beds). We evaluated S. aureus contamination of the hand rims of 20 wheelchairs 
using the swab or gauze wipe method to determine which method yielded a higher $S$. aureus detection rate. Subsequently, the handles of 20 wheelchairs were examined by wiping with gauze. In addition, the hand rims of 10 wheelchairs were wiped with ethanol for disinfection, and microbial contamination was then evaluated. An interview survey of nurses was also performed to determine the status of use of shared wheelchairs on the wards.

Figure 1. Wheelchair

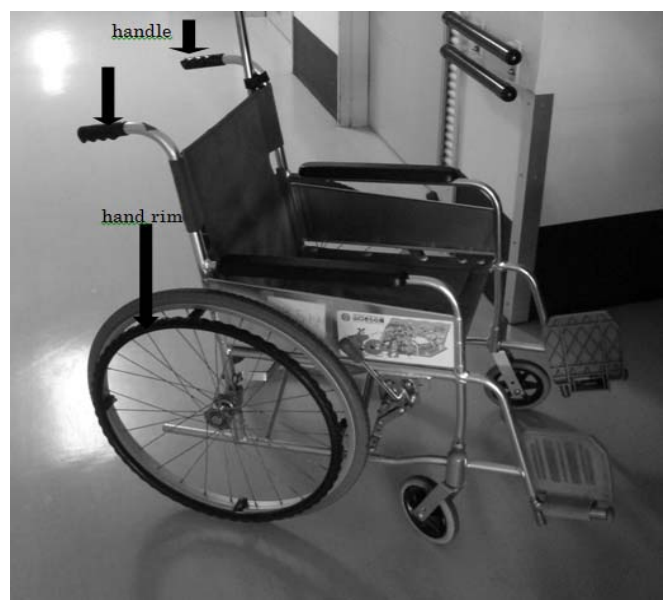

\subsection{Quantification of MRSA and methicillin-sensitive S. aureus (MSSA) and total bacterial count on surfaces wiped with swabs}

The surface of each wheelchair hand rim was wiped using a swab moistened with sterile physiological saline. The swab used for wiping was then placed in a tube containing $1 \mathrm{~mL}$ of sterile physiological saline. The tube was manually stirred for about $5 \mathrm{~s}$ and ultrasonicated (Sine Sonic 100, Ikemoto Rikagaku Co., Tokyo, Japan) at $36 \mathrm{kHz}$ for $10 \mathrm{~min}{ }^{[10]}$. Each sample was diluted 10-fold, 100 -fold, and 1000 -fold in sterile saline; two aliquots ( $0.2 \mathrm{~mL}$ each) of a diluted and an undiluted sample were plated on one salt egg yolk agar plate (Nissui Pharmaceutical, Co., Tokyo, Japan) and one Trypticase Soy Agar ${ }^{\circledR}$ (Nippon Becton Dickinson Co., Tokyo, Japan). These media were incubated for $48 \mathrm{~h}$ at $35^{\circ} \mathrm{C}$, and colony-forming units (cfu) were then counted. Yellow colonies on the plates with a pearl-ring formation in the surrounding medium were subjected to Gram staining, morphological examination, the coagulase test (STAPHYLO LA SEIKEN ${ }^{\circledR}$, Denka Seiken Co., Tokyo, Japan), and testing with an Api Staph ${ }^{\circledR}$ (Analytab Products, Plain View, New York, USA) to determine whether they were S. aureus. The cfu count on the Trypticase Soy Agar ${ }^{\circledR}$ was regarded as the total bacterial count.

The methicillin sensitivity of cultured $S$. aureus was determined using an MRSA screening agar containing $6 \mu \mathrm{g} / \mathrm{mL}$ of oxacillin (Nippon Becton Dickinson Co., Tokyo, Japan). When 10 or more cfu of $S$. aureus were detected, 10 colonies were randomly selected and their methicillin sensitivity was determined. The MRSA or MSSA count per wheelchair hand rim was estimated from the ratio of methicillin-resistant to methicillin-sensitive colonies.

\subsection{Quantification of MRSA and MSSA and total bacterial count on surfaces wiped with gauze}

The surface of each wheelchair hand rim and handle was wiped using sterile gauze $(10 \times 20 \mathrm{~cm})$ moistened with sterile physiological saline. The gauze used for wiping was placed in a $100 \mathrm{~mL}$ bottle containing $20 \mathrm{~mL}$ of sterile physiological saline. This bottle was manually stirred for about $5 \mathrm{~s}$ and ultrasonicated (Sine Sonic 100, Ikemoto Rikagaku Co., Tokyo, Japan) at $36 \mathrm{kHz}$ for $10 \mathrm{~min}$. Each sample was diluted 10-fold, 100-fold, and 1000-fold in sterile saline; two aliquots $(0.5 \mathrm{~mL}$ each) of a diluted and an undiluted sample were plated on one salt egg yolk agar plate and one Trypticase Soy $\operatorname{Agar}^{\circledR}$. In addition, the remaining saline sample $(c a .19 \mathrm{~mL})$ in the bottle was filtered through a $0.22 \mu \mathrm{m}$ membrane filter 
(diameter $5 \mathrm{~cm}$; Nippon Becton Dickinson Co., Tokyo, Japan) that was placed on salt egg yolk agar plates and incubated for $48 \mathrm{~h}$ at $35^{\circ}{ }^{[11]}$. Methods for the identification of $S$. aureus and the methicillin sensitivity of $S$. aureus were similar between the two wiping methods, i.e., with swabs or gauze.

When the membrane filtration technique revealed 20 or fewer cfu of $S$. aureus, the results obtained using this technique were regarded as $S$. aureus counts on the surface. When the membrane filtration technique revealed more than about $20 \mathrm{cfu}$ (when S. aureus cfu could not be counted), S. aureus counts on the surface were calculated from the diluted inocula on egg yolk agar.

\subsection{Evaluation of the effects of wiping with ethanol for disinfection}

The right hand rims of 10 wheelchairs were wiped twice with sterile gauze $(10 \times 20 \mathrm{~cm})$ soaked in $80 \%$ (v/v) ethanol (Ethanol IP for Disinfection, Kenei Pharmaceutical Co. Ltd., Osaka, Japan) at an interval of $1 \mathrm{~min}$, and after $1 \mathrm{~min} S$. aureus contamination was evaluated by wiping with gauze. The left hand rim was used as a control on which $S$. aureus contamination was also evaluated without wiping with $80 \%$ (v/v) ethanol.

\subsection{Statistical analysis}

Statistical differences were analyzed using the Wilcoxon U-test.

\section{Results}

An interview survey of nurses on the status of shared wheelchair use in the hospital showed that the wheelchairs did not receive regular cleaning or disinfection. The wheelchairs were kept in ward corridors, and each was used approximately once daily or once every 2 days.

Table 1. S. aureus contamination of wheelchair hand rims* found by wiping with a swab or gauze

\begin{tabular}{|c|c|c|c|c|c|c|c|c|c|c|}
\hline \multirow{3}{*}{ Contaminants } & \multicolumn{5}{|l|}{ Wiping with a swab } & \multicolumn{5}{|l|}{ Wiping with gauze } \\
\hline & \multirow{2}{*}{$\begin{array}{l}\text { No. of wheelchair } \\
\text { hand rims } \\
\text { contaminated/No. } \\
\text { of wheelchair hand } \\
\text { rims examined (\%) }\end{array}$} & \multicolumn{4}{|c|}{$\begin{array}{l}\text { No. of wheel chairs contaminated at a } \\
\text { density (cfu/wheelchair hand rim) }\end{array}$} & \multirow{2}{*}{$\begin{array}{l}\text { No. of wheelchair hand } \\
\text { rims contaminated/No. } \\
\text { of wheelchair hand rims } \\
\text { examined (\%) }\end{array}$} & \multicolumn{4}{|c|}{$\begin{array}{l}\text { No. of wheelchairs contaminated at a density } \\
\text { (cfu/wheelchair hand rim) }\end{array}$} \\
\hline & & 1-9 & 10-99 & 100-999 & $1,000-9,999$ & & $1-9$ & $10-99$ & 100-999 & $1,000-9,999$ \\
\hline MSSA & $10 / 20(50.0 \%)$ & 2 & 7 & 1 & 0 & $12 / 20(60.0 \%)$ & 2 & 9 & 1 & 0 \\
\hline MRSA & $14 / 20(70.0 \%)$ & 3 & 10 & 1 & 0 & $11 / 20(55.0 \%)$ & 2 & 4 & 4 & 1 \\
\hline $\begin{array}{l}\text { MSSA and } \\
\text { MRSA }\end{array}$ & $6 / 20(30.0 \%)$ & 0 & 4 & 2 & 0 & $6 / 20(30.0 \%)$ & 0 & 2 & 3 & 1 \\
\hline $\begin{array}{l}\text { MSSA and/or } \\
\text { MRSA }\end{array}$ & 18/20 (90.0\%) & 4 & 12 & 2 & 0 & 17/20 (85.0\%) & 2 & 9 & 5 & 1 \\
\hline
\end{tabular}

*The two hand rims (left and right) of each wheelchair were counted as one hand rim of each wheelchair.

Table 1 shows the $S$. aureus contamination of wheelchair hand rims found by wiping with a swab or gauze. When the hand rims of 20 wheelchairs were wiped with a swab, MSSA and/or MRSA were detected on 18 (90.0\%) and MRSA on 14 (70.0\%). The highest density of $S$. aureus was $220 \mathrm{cfu} / \mathrm{hand}$ rim. The mean $\pm \mathrm{SD}$ total bacterial count was $3,483.5 \pm 3,429.5$ (range 65-1.2 $\times 10^{4}$ ) cfu/hand rim. On the other hand, when the hand rims of 20 wheelchairs were wiped with gauze, S. aureus (MSSA and/or MRSA) was detected on 17 (85.0\%) and MRSA on 11 (55.0\%). The highest density of $S$. aureus was $2.8 \times 10^{3} \mathrm{cfu}$, and the total bacterial count was 109,010.0 $\pm 219,080.0$ (range $4 \times 10^{3}-8.6 \times 10^{5}$ ) cfu/hand rim. A comparison between the two wiping methods showed no significant difference in the density of $S$. aureus (MSSA and/or MRSA), MSSA alone, MRSA alone, or MRSA and MSSA detected but there was a significant difference in the total bacterial count $(p<0.0001)$. The detection rate therefore did not differ significantly between the two methods. When 
the handles of 20 wheelchairs were wiped with gauze, S. aureus (MSSA and/or MRSA) was detected on 4 (20.0\%) and MRSA on 3 (15.0\%). S. aureus density was $15.8 \pm 18.4$ (range 1-40) cfu/handle (Table 2). S. aureus was not detected on any of the 10 hand rims wiped with ethanol for disinfection after 1 min (Table 3).

Table 2. S. aureus contamination of wheelchair handles*found by wiping with gauze

\begin{tabular}{|c|c|c|c|c|c|}
\hline \multirow{2}{*}{ Contaminants } & \multirow{2}{*}{$\begin{array}{l}\text { No. of wheelchair handles } \\
\text { contaminated/No. of wheelchair } \\
\text { handles examined (\%) }\end{array}$} & \multicolumn{4}{|c|}{$\begin{array}{l}\text { No. of wheelchairs contaminated } \\
\text { at a density (cfu/wheelchair handle) }\end{array}$} \\
\hline & & $1-9$ & $10-99$ & 100-999 & $1,000-9,999$ \\
\hline MSSA & $1 / 20(5.0 \%)$ & 0 & 1 & 0 & 0 \\
\hline MRSA & $3 / 20(15.0 \%)$ & 2 & 1 & 0 & 0 \\
\hline MSSA and MRSA & $0 / 20(0.0 \%)$ & 0 & 0 & 0 & 0 \\
\hline MSSA and/or MRSA & $4 / 20(20.0 \%)$ & 2 & 2 & 0 & 0 \\
\hline
\end{tabular}

* The two handles (left and right) of each wheelchair were counted as one handle of each wheelchair.

Table 3. MSSA/MRSA contamination of wheelchair hand rims* and the effects of wiping with $80 \%$ (v/v) ethanol

\begin{tabular}{|c|c|c|c|c|c|c|}
\hline \multirow{2}{*}{ Contaminants } & \multirow{2}{*}{ Disinfection } & \multirow{2}{*}{$\begin{array}{l}\text { No. of wheelchair hand rims } \\
\text { contaminated/No. of } \\
\text { wheelchair hand rims } \\
\text { examined (\%) }\end{array}$} & \multicolumn{4}{|c|}{$\begin{array}{l}\text { No. of wheelchairs contaminated at a } \\
\text { density (cfu/wheelchair hand rim) }\end{array}$} \\
\hline & & & $1-9$ & 10-99 & 100-999 & $1,000-9,999$ \\
\hline \multirow{2}{*}{ MSSA and/or MRSA } & wiped with ethanol $\dagger$ & $0 / 10(0.0 \%)$ & 0 & 0 & 0 & 0 \\
\hline & Control & $4 / 10(40.0 \%)$ & 0 & 3 & 1 & 0 \\
\hline \multirow{2}{*}{ MRSA } & wiped with ethanol & $0 / 10(0.0 \%)$ & 0 & 0 & 0 & 0 \\
\hline & Control & $3 / 10(30.0 \%)$ & 0 & 2 & 1 & 0 \\
\hline
\end{tabular}

*The right hand rims of wheelchairs were wiped with ethanol for disinfection. The left hand rim was used as a control without wiping with ethanol for disinfection.

†The hand rims of wheelchairs were wiped twice with sterile gauze soaked in $80 \%(\mathrm{v} / \mathrm{v})$ ethanol at an interval of 1 minute.

$¥$ The left hand rim was used as a control without wiping with $80 \%$ (v/v) ethanol.

\section{Discussion}

The three main methods to detect environmental microbial contamination use a swab ${ }^{[1,8,12,13,14,15,16]}$, gauze wipe ${ }^{[3,17,18]}$, and agar plate ${ }^{[19,20]}$. The agar plate method is not appropriate for evaluating the contamination of the handles or hand rims of wheelchairs. Therefore, we compared the level of $S$. aureus contamination detected using the swab and gauze wipe methods. The density of $S$. aureus (MSSA and/or MRSA) detected was $47.2 \pm 66.2$ (range 5-220) cfu/hand rim using a swab and $242.4 \pm 661.2$ (range 2-2,780) cfu/hand rim using a gauze wipe. Although no significant difference was observed, the mean $S$. aureus density found using a gauze wipe was 5 -fold that using a swab. The total bacterial count found differed significantly between the two methods. The swab method is widely used due to its straightforwardness in studies on environmental contaminants. However, the results of this study showed that the gauze wipe method is more useful than the swab method.

Using the gauze wipe method, the hand rims of wheelchairs examined in this study were frequently found to be contaminated with MRSA (11/20 wheelchairs, 55.0\%). The highest MRSA density was $2.8 \times 10^{3} \mathrm{cfu} / \mathrm{hand}$ rim. On the other hand, a previous study showed that MRSA was detected on $8.7 \%$ of door handles of hospital rooms at a density of $1-6 \times 10^{3}$ cfu/handle ${ }^{[3]}$. Another study detected MRSA on $38 \%$ of side rails of beds at a density of $1-197$ cfu/bed $^{[17]}$. The 
density of MRSA contamination on the hand rims of wheelchairs found in this study was similar to that on the handles of hospital doors ${ }^{[3,17]}$.

Since wheelchairs as well as door handles of hospital rooms are sometimes contaminated with high levels of MRSA, regular disinfection is indispensable. After the wheelchair hand rims were wiped with ethanol for disinfection, no $S$. aureus was detected. Therefore, when wheelchairs are shared by patients, wiping with ethanol for disinfection after each use can prevent the transmission of MRSA ${ }^{[21,22]}$. Both the incidence and level of contamination were lower on the handles than on the hand rims of wheelchairs. This may be because the surface area of the handles is smaller than that of the hand rims and patients touch the handles less frequently.

\section{Conclusion}

The hand rims of wheelchairs examined in this study were frequently found to be contaminated with MRSA (11/20 wheelchairs, 55.0\%). The highest MRSA density was $2.8 \times 10^{3} \mathrm{cfu} /$ hand rim. The incidence of $S$. aureus contamination and its density were therefore higher on hand rims than on handles. After the hand rims were disinfected by wiping with $80 \%$ (v/v) ethanol, S. aureus was not detected on any of them. Since S. aureus may potentially be transmitted via shared wheelchairs, their disinfection after every use is recommended.

\section{Acknowledgments}

The authors thank Dr. Akihiro Sawa of Hiroshima International University, Hiroshima, Japan, for her help and support in statistical analysis.

\section{Conflict of interests}

We declare that we have no conflict of interests.

\section{References}

[1] Boyce JM, Potter-Bynoe G, Chenevert C, King T. Environmental contamination due to methicillin-resistant Staphylococcus aureus: possible infection control implications. Infect Control Hosp Epidemiol. 1997; 18: 622-627. PMid:9309433 http://dx.doi.org/10.1086/647686

[2] Blythe D, Keenlyside D, Dawson SJ, Galloway A. Environmental contamination due to methicillin-resistant Staphylococcus aureus (MRSA). J Hosp Infect. 1998; 38: 67-70. http://dx.doi.org/10.1016/S0195-6701(98)90176-1

[3] Oie S, Hosokawa I, Kamiya A. Contamination of room door handles by methicillin-sensitive/methicillin-resistant Staphylococcus aureus. J Hosp Infect. 2002; 51: 140-143. PMid:12090803 http://dx.doi.org/10.1053/jhin.2002.1221

[4] Cohen HA, Amir J, Matalon A, Mayan R, Beni S, Barzilai A. Stethoscopes and otoscopes-a potential vector of infection? Fam Pract. 1997; 14: 446-448. PMid:9476074 http://dx.doi.org/10.1093/fampra/14.6.446

[5] French G, Rayner D, Branson M, Walsh M. Contamination of doctors’ and nurses’ pens with nosocomial pathogens. Lancet. 1998; 351: 213. http://dx.doi.org/10.1016/S0140-6736(05)78182-4

[6] Banerjee D, Fraise A, Chana K. Writing pens are an unlikely vector of cross-infection with methicillin-resistant Staphylococcus aureus (MRSA). J Hosp Infect. 1999: 43: 73-75. PMid:10462644 http://dx.doi.org/10.1053/jhin.1999.0621

[7] Berman DS, Shaefler S, Simberkoff MS, Rahal JJ. Tourniquets and nosocomial methicillin-resistant Staphylococcus aureus infections. N Engl J Med. 1986; 315: 514-515. PMid:3637628 http://dx.doi.org/10.1056/NEJM198608213150812

[8] Devine J, Cooke RPD, Wright EP. Is methicillin-resistant Staphylococcus aureus (MRSA) contamination of ward-based computer terminals a surrogate marker for nosocomial MRSA transmission and handwashing compliance? J Hosp Infect. 2001; 48: 72-75. PMid:11358473 http://dx.doi.org/10.1053/jhin.2001.0955

[9] Bures S, Fishbain JT, Uyehara CFT, Parker JM, Berg BW. Computer keyboards and faucet handles as reservoirs of nosocomial pathogens in the intensive care unit. Am J Infect Control. 2000; 28: 465-471. PMid:11114617

http://dx.doi.org/10.1067/mic.2000.107267 
[10] Jeng DK, Lin LI, Hervey LV. Importance of ultrasonication conditions in recovery of microbial contamination from material surfaces. J Appl Bacteriol. 1990; 68: 479-484. http://dx.doi.org/10.1111/j.1365-2672.1990.tb02899.x

[11] Oie S, Kamiya A. Survival of methicillin-resistant Staphylococcus aureus (MRSA) on naturally contaminated dry mops. J Hosp Infect. 1996; 34: 145-149. http://dx.doi.org/10.1016/S0195-6701(96)90140-1

[12] Millar MR, Keyworth N, Lincoln C, King B, Congdon P. 'Methicillin-resistant' Staphylococcus aureus in a regional neonatology unit. J Hosp Infect. 1987; 10: 187-197. http://dx.doi.org/10.1016/0195-6701(87)90146-0

[13] Cookson B, Peters B, Webster M, Phillips I, Rahman M, Nobel W. Staff carriage of epidemic methicillin-resistant Staphylococcus aureus. J Clin Microbiol. 1989; 27: 1471-1476. PMid:2768437

[14] Ndawula EM, Brown L. Mattresses as reservoirs of epidemic methicillin-resistant Staphylococcus aureus. Lancet. $1991 ; 337: 488$. http://dx.doi.org/10.1016/0140-6736(91)93420-E

[15] Haddad Q, Sobayo EI, Basit OBA, Rotimi VO. Outbreak of methicillin-resistant Staphylococcus aureus in a neonatal intensive care unit. J Hosp Infect. 1993; 23: 211-221. http://dx.doi.org/10.1016/0195-6701(93)90026-V

[16] Stacey A, Burden P, Croton C, Jones E. Contamination of television sets by methicillin-resistant Staphylococcus aureus (MRSA). J Hosp Infect. 1998; 39: 243-244. http://dx.doi.org/10.1016/S0195-6701(98)90266-3

[17] Oie S, Kamiya A. Contamination of environmental surfaces by methicillin-resistant Staphylococcus aureus (MRSA). Biomed Lett. 1998; 57: 115-119.

[18] Oie S, Yanagi C, Matsui H, Nishida T, Tomita M, Kamiya A. Contamination of environmental surfaces by Staphylococcus aureus in a dermatological ward and its preventive measures. Biol Pharm Bull. 2005; 28: 120-123. PMid:15635175 http://dx.doi.org/10.1248/bpb.28.120

[19] Craven DE, Reed C, Kollisch N, DeMaria A, Lichtenberg D, Shen K, McCabe WR. A large outbreak of infections caused by a strain of Staphylococcus aureus resistant to oxacillin and aminoglycosides. Am J Med. 1981; 71: 53-58. http://dx.doi.org/10.1016/0002-9343(81)90258-8

[20] Bradley SF, Terpenning MS, Ramsey MA, Zarins LT, Jorgensen KA, Sottile WS, Schaberg DR, Kauffman CA. Methicillin-resistant Staphylococcus aureus: colonization and infection in a long-term care facility. Ann Intern Med. 1991; 115, 417-422. PMid:1908198

[21] Rutala WA, Weber DJ. Should we routinely disinfect floors? Reply to Professor F. Daschner. J Hosp Infect. 2002 ; 51: 309-311. http://dx.doi.org/10.1053/jhin.2002.1228

[22] Rutala WA, Weber DJ. The benefits of surface disinfection. Am J Infect Control. 2004; 32: 226-231. PMid:15175619 http://dx.doi.org/10.1016/j.ajic.2004.04.197 